\title{
Analisa Kepatuhan Pengisian Berkas Rekam Medis di Instalasi Rawat Inap Rumah Sakit X
}

\section{Analysis of Medical Record Filling Completeness At Inpatient Care Facilitiy of $X$ Hospital}

\author{
Gita Kencana*, Grace Rumengan*, Fresley Hutapea* \\ Program Studi Administrasi Rumah Sakit, Program Pasca Sarjana \\ Universitas Respati Indonesia \\ Email : purnama_gita@yahoo.com, gwaturandang10@gmail.com, \\ fresleyhutapea@yahoo.com
}

\begin{abstract}
ABSTRAK
Rumah Sakit X sebagai salah satu lembaga pelayanan kesehatan di Kabupaten Bogor terus berupaya memberikan pelayanan terbaik kepada masyarakat, dimana penyelenggaraan rekam medis yang baik adalah salah satu kuncinya. Masalah yang sering timbul dalam penyelenggaraan rekam medis adalah dalam proses pengisian berkas yang tidak lengkap, terbukti dari didapatkanya angka tertinggi berkas rekam medis yang tidak lengkap adalah pada pengisian resume medis sebesar 27,5\%. Penelitian ini merupakan studi kualitatif dengan desain studi cross-sectional dengan pendekatan interpretative. Metode kualitatif dilakukan dengan wawancara mendalam (indepth interview) terhadap Direktur mengenai kebijakan rumah sakit tentang rekam medis, Petugas PPA, Petugas Rekam Medis dan Casemanager. Hasil. Seluruh petugas memahami pentingnya pengisian rekam medis dan sebagian memahami SPO yang terdapat dirumah sakit namun sosialisasi belum dijalankan menyeluruh. Sistem reward dan punishment belum diterapkan di rumah sakit tersebut. SPO dan SPM rekam medis berpengaruh kepada kepatuhan petugas dalam pengisian rekam medis, reward dan punishment berpengaruh tehadap sikap dan tanggung jawab dokter dalam kepatuhan pengisian rekam medis dan ukungan dari rekan kerja dapat memotivasi petugas dalam mengisi rekam medis.
\end{abstract}

Kata Kunci : Kepatuhan; Rekam Medis; Dokter; Petugas PPA.

\begin{abstract}
$X$ Hospital as one of the health service institutions in Bogor, continues to strive to provide the best service to the community, where the implementation of a good medical record is one of the keys. The problem that often arises in the implementation of medical records is that the process of filling it is incomplete, as evidenced by the acquisition of the highest number of incomplete medical record files is on medical resume filling of $27.5 \%$. This research is a qualitative study with a cross-sectional study design with an interpretative approach. The qualitative method was carried out by in-depth interviews with the Directors regarding hospital policies regarding medical records, PPA officers, Medical Record Officers and Case manager. Results. All officers understood the importance of filling out medical records and some understood SPO at the hospital but socialization had not been carried out thoroughly. The reward and punishment system has not been implemented in the hospital. SPO and SPM medical records affect the compliance of officers in filling out medical records, reward and punishment has an effect on the attitudes and responsibilities of doctors in compliance with filling in medical records and support from colleagues can motivate officers to fill in medical records.
\end{abstract}

Keywords : Compliance; Medical Record; Doctor; Proffesional Caregivers Starff. 
Gita Kencana, Grace Rumengan, Fresley Hutapea : Analysis of Medical Record Filling ....

\section{PENDAHULUAN}

Berdasarkan Undang-Undang Republik Indonesia Nomor 44 tahun 2009 tentang Rumah Sakit (RS), Rumah Sakit adalah institusi pelayanan bagi masyarakat dengan karakteristik tersendiri yang dipengaruhi oleh ilmu pengetahuan kesehatan, kemajuan teknologi dan kehidupan sosial ekonomi masyarakat serta harus mampu meningkatkan pelayanan yang lebih bermutu dan terjangkau oleh masyarakat agar terwujud derajat kesehatan yang paripurna. Mutu pelayanan merupakan suatu hal yang sangat penting untuk tetap dapat menjaga keberadaan suatu rumah sakit. Salah satu parameter untuk menentukan kualitas pelayanan medis Rumah Sakit adalah pelayanan rekam medis.

Rekam medis merupakan bagian dari arsip yang menggambarkan segala aktivitas oleh sebuah instansi dalam kurun waktu tertentu. Rumah Sakit harus memiliki rekam medis sebagai suatu standar pelayanan bidang kesehatan yang berguna untuk peningkatan kualitas dalam memberikan pelayanan yang optimal terhadap pasien. Menurut Permenkes 269 Tahun 2008 Rekam Medis adalah berkas berisi catatan dan dokumen tentang identitas pasien, pemeriksaan, pengobatan, tindakan dan pelayanan lain yang telah diberikan kepada pasien. Tenaga yang berhak mengisi rekam medis antara lain dokter umum, dokter spesialis, dokter gigi, dan dokter gigi spesialis, dokter tamu yang merawat pasien di rumah sakit, residens yang sedang melaksanakan praktek, tenaga paramedis perawatan dan paramedis non perawatan (Depkes RI, 2008).

Masalah yang sering timbul dalam pengisian rekam medis adalah dalam proses pengisiannya tidak lengkap, penulisan dokter yang kurang spesifik mengenai diagnosa. Keadaan ini mengakibatkan dampak bagi intern dan ekstern rumah sakit, karena hasil pengolahan data menjadi dasar pembuatan laporan intern rumah sakit dan laporan ekstern rumah sakit. Laporan ini berkaitan dengan penyusunan berbagai perencanaan rumah sakit, pengambilan keputusan oleh pimpinan khususnya evaluasi pelayanan yang telah diberikan yang diharapkan hasil evaluasinya menjadi lebih baik (Gyana, 2012).

Sistem rekam medis di Rumah Sakit X sudah memanfaatkan sistem informasi berbasis komputer namun masih hanya terbatas pada registrasi pasien. Sedangkan untuk rekam medis masih diselenggarakan secara manual dengan kertas catatan medik pasien yang meliputi data identitas pasien, data tanggal dan waktu, data dokter, data anamnesis dan catatan medik, data pemeriksaan intraoral dan ekstraoral, data diagnosa, data rencana perawatan, data tindakan, serta nama dan tanda tangan operator yang merawat, dan tanda tangan penanggung jawab. 
Berdasarkan observasi yang dilakukan terhadap total 50 rekam medis pasien rawat inap periode Januari - Maret 2018 terdapat ketidaklengkapan pengisian rekam medis terutama lembar resume medis menempati angka yang tertinggi sebesar 27, 5\%

\section{METODE}

Metode yang digunakan dalam penelitian ini adalah metode deskriptif kualitatif cross-sectional yang berusaha memberikan gambaran sekaligus menerangkan fenomena-fenomena yang ada sebagai prosedur pemecahan masalah yang dialami oleh RS X Bogor pada penelitian ini dilaksanakan.

Penelitian dengan menggunakan metode kualitatif yang umunya berangkat dari pertanyaan why atau how. Untuk itu teknik penelitian yang digunakan peneliti dengan studi kasus, karena permasalahan yang diteliti lebih sesuai apabila menggunakan studi kasus. Penelitian ini, peneliti mengamati masalah rekam medis yang masih belum lengkap pada instalasi rawat inap RS X. Penelitian dilakukan selama bulan Mei - Juli 2018 di Rumah Sakit X.

Subjek penelitian inilah yang memberikan berbagai informasi dari informan yang diperlukan selama proses penelitian. Yang menjadi informan penelitian, yaitu pertama, Direktur, seseorang yang membuat kebijakan rekam medis di rumah sakit. Kedua, DPJP adalah Dokter Penanggung Jawab Pelayanan di ruang rawat inap. Ketiga, Dokter Jaga Ruangan, yaitu Dokter Umum yang membantu DPJP di ruang rawat inap pada saat shift. Keempat, Perawat yaitu perawat yang sedang bertugas pada shiftnya di ruang rawat inap. Kelima, Case manager adalah petugas yang bertanggung jawab sebagai koordinator atas kelengkapan berkas rekam medis pasien selama pasien dalam perawatan. Keenam, Petugas Rekam Medis ialah petugas yang disumpah untuk bertanggung jawab atas berkas rekam medis.

\section{HASIL}

Pengambilan data pada penelitian ini melalui wawancara secara mendalam kepada pihak-pihak yang berhubungan dengan analisis kelengkapan berkas rekam medis dalam rangka mengukur kepatuhan pengisian berkas rekam medis di Instalasi Rawat Inap Rumah Sakit X. Dimana pertanyaannya terkait dengan pengetahuan petugas seperti diantaranya tentang pengertian rekam medis itu sendiri, SPO dan SPM rekam medis, 
desain form rekam medis, tentang sikap dan tanggung jawab yang dituangkan kedalam pertanyaan tentang pemberian reward dan punishment oleh rumah sakit, dan juga dukungan dari rekan kerja. Secara keseluruhan hasil wawancara dilampirkan dalam bentuk matriks dan untuk panduan observasi, diisi dengan checklist mengenai kelengkapan berkas rekam medis rawat inap di Rumah Sakit X bulan Januari - Maret 2018.

Tabel 1. Pengetahuan tentang SPO dan SPM Rekam Medis serta Desain Form Rekam Medis di RS X

\begin{tabular}{|c|c|c|c|}
\hline Pernyataan & DPJP & Dokter Jaga & Perawat \\
\hline $\begin{array}{l}\text { Pengetahuan tentang SPO dan SPM rekam medis } \\
\text { di RS X }\end{array}$ & $60 \%$ & $75 \%$ & $50 \%$ \\
\hline $\begin{array}{l}\text { Tidak pernah tau adanya sosialisasi tentang } \\
\text { pengisian rekam medis RS X }\end{array}$ & $100 \%$ & $100 \%$ & - \\
\hline $\begin{array}{l}\text { Mengetahui/paham tentang isi kelengkapan rekam } \\
\text { medis }\end{array}$ & $100 \%$ & $100 \%$ & $100 \%$ \\
\hline $\begin{array}{l}\text { Desain/formulir rekam medis sudah cukup jelas } \\
\text { dan sesuai }\end{array}$ & $80 \%$ & $100 \%$ & $100 \%$ \\
\hline $\begin{array}{l}\text { Mengetahui seberapa pentingnya berkas rekam } \\
\text { medis }\end{array}$ & $100 \%$ & $100 \%$ & $100 \%$ \\
\hline
\end{tabular}

Tabel 2. Sikap dan Tanggung Jawab Petugas dalam pengisian Rekam Medis

\begin{tabular}{|c|c|c|c|}
\hline Pertanyaan & DPJP & Dokter Jaga & Perawat \\
\hline $\begin{array}{l}\text { Mengetahui siapa yang bertanggung jawab dalam } \\
\text { mengisi rekam medis dan resume medis }\end{array}$ & $100 \%$ & $100 \%$ & $100 \%$ \\
\hline $\begin{array}{l}\text { Penulisan asuhan keperawatan sesuai dengan } \\
\text { instruksi dokter }\end{array}$ & - & - & $100 \%$ \\
\hline Waktu pengisian rekam medis setelah visit & $100 \%$ & $100 \%$ & - \\
\hline $\begin{array}{l}\text { Segera mengisi berkas RM bila ada yang } \\
\text { tertinggal/ lupa mengisi }\end{array}$ & $100 \%$ & $100 \%$ & $100 \%$ \\
\hline $\begin{array}{l}\text { Melengkapi berkas RM terlebih dahulu sebelum } \\
\text { dikembalikan ke unit RM }\end{array}$ & - & - & $50 \%$ \\
\hline Tidak mendapat reward \& punishment & $100 \%$ & $100 \%$ & $100 \%$ \\
\hline Mengisi RM sesuai SPO & $100 \%$ & $100 \%$ & - \\
\hline
\end{tabular}

Tabel 3. Dukungan Rekan terhadap Pengisian Berkas Rekam Medis

\begin{tabular}{lccc}
\hline \multicolumn{1}{c}{ Pertanyaan } & DPJP & Dokter Jaga & Perawat \\
\hline $\begin{array}{l}\text { Perlunya diingatkan oleh teman sejawat/ tenaga } \\
\text { kesehatan lain ataupun manajemen untuk } \\
\text { melengkapi rekam medis. }\end{array}$ & $80 \%$ & $100 \%$ & $80 \%$ \\
$\begin{array}{l}\text { Merasa wajib membantu memonitor dokter dalam } \\
\text { pengisian rekam medis }\end{array}$ & - & - & $80 \%$ \\
\hline
\end{tabular}


Tabel 4. Ketidaklengkapan Pengisian Rekam Medis Pasien Rawat Inap Berdasarkan Nama Lembar Rekam Medis

\begin{tabular}{lcc}
\hline \multicolumn{1}{c}{ Nama Lembar RM } & Tidak Lengkap & Tidak Lengkap \\
& Jan-Mar 2018 & Mei-Jul 2018 \\
& $(\%)$ & $(\%)$ \\
\hline Pemeriksaan Fisik & 17,5 & 3 \\
Pemeriksaan Penunjang & 11,6 & 8,12 \\
Resume Pulang & 27,5 & 18,12 \\
\hline
\end{tabular}

Sebagai data penunjang, peneliti mengambil 50 sample rekam medis bulan Mei sampai dengan Juli 2018 untuk dibandingkan dengan observasi awal yang kami ambil. Berdasarkan data yang kami ambil tersebut, masih terdapat lembar rekam medis yang tidak lengkap pengisiannya, yaitu lembar resume yang pada awal sebesar 27, 5\% menjadi 18, 12\%. Selain lembar resume medis, lembar pemeriksaan penunjang dan pemeriksaan fisik pun masih ada yang tidak lengkap pengisiannya.

\section{PEMBAHASAN}

Hasil penelitian di Rumah Sakit X Leuwiliang dapat diketahui berbagai informasi dan data tentang keadaan tersebut. Hasil penelitian kami melalui wawancara mendalam dengan responden, seluruh responden memiliki pengetahuan tentang rekam medis. $60 \%$ responden DPJP mengetahui dan paham tentang SPO rekam medis yang ada di RS X, sementara dari responden dokter umum hanya 75\% dan 50\% dari perawat. Seluruhnya mengatakan belum ada sosialisasi tentang penulisan rekam medis di RS tersebut, mereka mengatakan hanya mengetahui SPO rekam medis secara umum atau dari tempat praktek di rumah sakit lain. Seluruhnya mengatakan paham tentang kelengkapan rekam medis.

Menurut Edna K. Huffman (Health Information Management, Physician Record Co, 1994) Rekam Medis adalah Kumpulan dari fakta-fakta atau bukti keadaan pasien, riwayat penyakit dan pengobatan masa lalu serta saat ini yang di tulis oleh profesi kesehatan yang memberikan pelayanan pada pasien tersebut.

Adanya sosialisasi tentang definisi rekam medis, kegunaannya serta pentingnya rekam medis dapat membuat petugas lebih patuh dalam mengisi berkas rekam medis. Sebanyak 80\% responden DPJP mengatakan desain form cukup jelas, 20\% lainnya mengatakan bahwa form rekam medis perlu dibuat lebih sederhana. Responden mengatakan, agar form rekam medis bisa lebih disederhanakan lagi, menyesuaikan 
dengan tipe rumah sakit X yaitu type D. Sebanyak 100\% responden dokter umum dan perawat mengatakan bahwa formulir cukup jelas dan sesuai.

Desain yang terlalu panjang, membuat petugas malas untuk mengisi rekam medis. Dengan membuat desain form yang lebih sederhana, dapat membantu petugas agar mengisi rekam medis dengan lengkap. Sebanyak 100\% responden memahami bahwa rekam medis adalah berkas yang sangat penting bagi sebuah rumah sakit.

Kelengkapan dalam pengisian berkas rekam medis oleh dokter dapat memudahkan tenaga kesehatan lain dalam memberikan tindakan atau pengobatan pada pasien, dan dapat dijadikan sebagai sumber data pada bagian rekam medis dalam pengelolaan data dan laporan yang dijadikan informasi yang berguna bagi pihak manajemen rumah sakit dalam menentukan evaluasi dan pengembangan pelayanan kesehatan (Hatta, 2012).

Secara umum, mengenai Desain Formulir Rekam Medis yang ada di Rumah Sakit $\mathrm{X}$ sudah cukup jelas dan sesuai, senada dengan yang dikatakan oleh $80 \%$ responden DPJP, mengingat RS X merupakan rumah sakit tipe D, maka berkas rekam medis masih bisa dibuat lebih sederhana dan beberapa point tidak perlu dicantumkan karena tidak pernah dilakukan tindakan di rumah sakit tipe D. Dengan demikian, diharapkan semua berkas rekam medis bisa terisi lengkap, jelas dan tepat waktu sesuai dengan SPO dan SPM Rekam Medis yang telah ditetapkan oleh rumah sakit.

Pada wawancara mendalam yang dilakukan di RS X terhadap dokter dan petugas PPA, pada dasarnya semua responden mengatakan bahwa tanggung jawab pengisian rekam medis ada pada petugas professional pemberi asuhan utamanya yaitu dokter spesialis, dokter umum, perawat dan tenaga kesehatan lain yang pada saat itu melayani pasien secara langsung dan pada telaah data rekam medis bulan Juni dan Juli yang diambil peneliti, masih terdapat ketidaklengkapan resume medis sebesar 10, 25\%.

Secara sikap, dokter dan petugas PPA lainnya sudah menyadari tanggungjawabnya terhadap kelengkapan isi rekam medis sebagai mana tertuang di manual rekam medis yang diterbitkan oleh Konsil Kedokteran Indonesia tahun 2006. Namun demikian, ketidak lengkapan berkas resume medis rawat inap yang di temukan pada periode bulan Juni Juli sebesar 10, 25\% masih dikatakan cukup tinggi, walaupun mengalami penurunan secara angka ketika dibandingkan dengan studi awal yang dilakukan pada bulan Januari Maret yang ditemukan ketidak lengkapan berkas rekam medis ada pada angka 27, 5\%. Akan ada banyak faktor yang dapat mempengaruhi masih tingginya ketidak lengkapan pengisian berkas rekam medis, salah satunya adalah faktor tanggung jawab dokter (Zaenal Sugiyanto, 2006). 
Sebanyak 100\% responden dokter menjawab bahwa mereka menulis rekam medis pada saat selesai visite. Kadang dokter terburu-buru dalam mengisi rekam medis karena jadwal yang dekat dengan jam praktek di poli dengan banyaknya pasien yang telah menunggu atau harus segera praktek di rumah sakit lain. Berdasarkan kesibukan dokter di RS ini, maka pengisian rekam medis tertunda.

Untuk pertanyaan wawancara kepada perawat mengenai pengembalian berkas rekam medis pada saat pasien pulang, setengahnya menjawab mereka langsung mengembalikan rekam medis ke unit rekam medik tanpa melengkapi lembar yang belum terisi, sementara sisanya menjawab melengkapi dulu rekam medis yang belum terisi sebelum mengembalikan ke unit rekam medik dalam waktu paling lama 2x24 jam.

Menurut Depkes (2008), rekam medis harus segera dibuat dan dilengkapi seluruhnya setelah pasien mendapatkan pelayanan dengan ketentuan setiap tidakan konsultasi yang dilakukan terhadap pasien, selambat-lambatnya dalam waktu 24 jam harus ditulis dalam lembar rekam medis. Pada pertanyaan mengenai reward dan punishment, $100 \%$ responden menjawab bahwa mereka tidak mendapat reward dan punishment dikarenakan di RS tersebut belum ada sistem pemberian reward dan punishment dalam kelengkapan pengisian rekam medis.

Di RS X belum menerapkan sistem pemberian reward dan punishment. Hal ini membuat para petugas menganggap bahwa ketidaklengkapan rekam medis bukan merupakan masalah yang besar. Sebanyak 100\% responden dokter mengatakan bahwa mereka mengisi rekam medis sesuai SPO. Dari data yang diambil bulan Juni-Juli 2018 didapatkan masih ada 10,25\% berkas RM yang tidak lengkap, ini berarti masih ada beberapa petugas yang mengisi rekam medis tidak sesuai SPO.

Berdasarkan wawancara mendalam kepada Dokter DPJP, Dokter Jaga, dan Perawat dengan pertanyaan tentang tanggung jawab mengisi rekam medis, 100\% responden mengatakan kewajiban mengisi rekam medis ada pada dokter penanggung jawab, dan juga menjadi tanggung jawab perawat bahkan bagian pendaftaran dan petugas rekam medis. Sebanyak $100 \%$ perawat mengatakan mereka menulis asuhan keperawatan sesuai dengan instruksi dokter.

Mengenai waktu pengisian rekam medis, 100\% dokter baik DPJP maupun dokter umum mengisi berkas rekam medis setelah visite. Dan seluruh dokter mengatakan segera mengisi berkas rekam medis yang tertinggal bila lupa. Di Rumah Sakit X, seringkali berkas rekam medis yang belum terisi lengkap langsung dikembalikan ke bagian rekam medis tanpa melengkapi terlebih dahulu, ini terlihat dari observasi awal di bagian rekam 
medik bahwa ada beberapa berkas yang masih tidak lengkap dan sejalan dengan hasil wawancara peneliti mendapatkan 50\% perawat mengatakan berkas rekam medis segera dikembalikan ke bagian rekam medik begitu pasien pulang, 50\% lainnya mengatakan akan melengkapi berkas rekam medis dan mengembalikannya pada waktu maksimal 2x24 setelah pasien pulang.

Pada wawancara mendalam yang dilakukan terhadap dokter dan petugas PPA ditemukan sebanyak 100\% responden DPJP dan dokter umum di RS X mengisi berkas rekam medis sesuai SPO yang mereka ketahui dari rumah sakit lain. Salah satu faktor yang mempengaruhi kepatuhan adalah dukungan rekan, dimana jika seseorang memiliki dukungan sosial dari teman mereka untuk tidak patuh, maka ketaatan mungkin berkurang. Juga kehadiran orang lain yang terlihat tidak mematuhi figur otoritas mengurangi tingkat ketaatan.

Dukungan rekan menempati posisi yang sangat strategis pengaruhnya terhadap kelengkapan pengisian berkas rekam medis yang dilakukan oleh dokter dan petugas PPA. Sejalan dengan hasil wawancara mendalam terhadap dokter dan petugas PPA yang bertugas di Instalasi Rawat Inap RS X bahwa sebagian besar responden mengatakan merasa perlu diingatkan oleh teman sejawat lain dalam hal mengisi rekam medis, jika didapati rekam medis yang lupa terisi atau terlewat karena kesibukan dokter dan petugas PPA, maka dokter dan petugas PPA akan langsung mengisi berkas rekam medis ketika diingatkan oleh petugas atau teman sejawat lain.

Adanya dukungan rekan adalah hal yang positif, karena dapat menciptakan lingkungan kerja yang supportif (saling mendukung dan mengoreksi dalam tujuan yang baik). Walau demikian, bukan berarti mengurangi nilai sikap dan tanggung jawab pribadi terhadap pengisian berkas rekam medis. Maka, diperlukan sikap tegas dari manajemen untuk mencapai penyelenggaraan rekam medis yang baik, yaitu rekam medis yang lengkap, informatif, dan tepat waktu.

Berdasarkan hasil wawancara mendalam yang dilakukan di Instalasi Rawat Inap Rumah Sakit X tentang kepatuhan pengisian rekam medis, hampir semua responden mengerti dan paham tentang rekam medis, namun belum pernah ada sosialisasi tentang pengisiannya yang baik dan benar.

Menurut Notoatmodjo (2007) bahwa salah satu faktor yang mempengaruhi keptuhan adalah pengetahuan, dimana definisi kepatuhan disini adalah pengetahuan adalah suatu proses dengan menggunakan pancaindra yang dilakukan seseorang terhadap objek tetentu dapat menghasilkan pengetahuan dan keterampilan (Hidayat, 2007). Sejalan 
dengan penelitian yang dilakukan, bahwa pengetahuan yang dimiliki oleh petugas di rumah sakit $\mathrm{X}$ dapat mempengaruhi kepatuhan dalam pengisian berkas rekam medis. Hanya perlu sosialisasi yang lebih menyeluruh terhadap petugas untuk lebih memaksimalkan pengisian berkas rekam medis tersebut.

Sikap dan tanggung jawab yang dimiliki oleh petugas pengisi rekam medis di rumah sakit $\mathrm{X}$ khususnya instalasi rawat inap cukup mempengaruhi kepatuhan petugas dalam mengisi rekam medis di rumah sakit tersebut. Dalam hal sikap dan tanggung jawab dan sikap petugas terhadap kepatuhan mengisi rekam medis, semua responden menyadari bahwa kewajiban mengisi rekam medis adalah pada DPJP walaupun beberapa mengatakan, seperti pendaftaran dan bagian rekam medik harus ikut terlibat.

Adanya dukungan dari rekan kerja yang seperti saling mengingatkan untuk mengisi rekam medis ternyata berpengaruh pada kepatuhan mengisi berkas rekam medis. Hal ini terlihat bahwa hampir seluruh responden mengatakan mereka merasa perlu untuk diingatkan dalam melengkapi berkas rekam medis.

Berdasarkan teori eksperimen Milgram bahwa beberapa faktor yang mempengaruhi kepatuhan adalah tanggung jawab, dimana Orang yang memiliki komitmen atau pribadi yang kuat, cenderung bersikap lebih patuh daripada yang memiliki komitmen rendah dan juga dukungan rekan dari teman sejawat mereka untuk saling mengingatkan dan ketika melihat temannya patuh maka mereka juga akan patuh. Sesuai dengan yang tergambar di instalasi rawat inap rumah sakit $\mathrm{X}$ dalam hal pengisian rekam medis.

Dari wawancara dengan manajemen rumah sakit, petugas rekam medis maupun case manajer, bahwa masi terdapat kendala saat memeriksa berkas rekam medis, yaitu masih terdapat beberapa berkas yang pengisiannya tidak lengkap. Hal ini membuat proses penyimpanan rekam medis menjadi terhambat, karena berkas rekam medis tersebut harus dikembalikan dulu ke instalasi rawat inap untuk dilengkapi. Manajemen mengatakan akan mengadakan sosialisasi tentang SPO rekam medis dan melakukan monitoring untuk memantau kelengkapan berkas rekam medis tersebut dan bila perlu akan diadakan pemberian reward dan juga punishment agar petugas lebih detail lagi mengisi rekam medis.

\section{SIMPULAN}

Berdasarkan penelitian yang dilakukan di Instalasi Rawat Inap RS X khususnya mengenai rekam medis, maka penulis mendapatkan kesimpulan bahwa seluruh dokter dan petugas PPA di RS X memahami tentang rekam medis, kelengkapannya serta pentingnya 
Gita Kencana, Grace Rumengan, Fresley Hutapea : Analysis of Medical Record Filling ....

berkas tersebut bagi suatu rumah sakit, dan beberapa mengetahui SPO yang ada, walaupun sosialisasi tentang SPO penulisan rekam medis belum menyeluruh namun seluruh responden mengetahui cara-cara penulisan rekam medis yang baik secara umum. Desain rekam medis di RS ini sudah cukup baik, walaupun masih terdapat beberapa point yang dianggap tidak perlu untuk dicantumkan, sehingga membuat dokter malas mengisi. Tanggung jawab dari petugas dalam pengisian berkas rekam medis masih dapat dikatakan kurang, ini dikatakan karena masih terdapat dokter maupun perawat yang tidak mengisi rekam medis dengan lengkap, walaupun sebenarnya para responden tau dan mengerti tentang rekam medis, ini dikarenakan belum adanya sistem pemberian reward dan punishment, sehingga mereka menganggap bila selama ini ada kekurangan dalam mengisi rekam medis itu bukanlah suatu masalah, serta masih diperlukan dukungan rekan, baik yang didapat dari rekan kerja sesama teman sejawat maupun manajemen untuk saling mengingatkan dalam mengisi rekam medis.

\section{UCAPAN TERIMA KASIH}

Ucapan terima kasih kami sampaikan kepada Program Studi Administrasi Rumah Sakit,Program Pasca Sarjana Universitas Respati Indonesia atas bimbingan dan dukungan kepada peneliti.

\section{DAFTAR PUSTAKA}

Budi, Savitri Citra. 2011. Manajemen Unit Kerja Rekam Medis. Quantum Sinergis Media. Yogyakarta.

Depkes RI Direktorat Jendral Pelayanan Medik, Pedoman Pengelolaan Rekam Medis Rumah Sakit di Indonesia, Revisi I, Jakarta, 1997

Fantri Pamugkas, 2014. Identifikasi Ketidaklengakapan Dokumen Rekam Medis Rawat Inap di RSUD Ngudi Waluyi Wlingi. Jurnal Kedokteran Brawijaya Vol.28, Suplemen No.2, 2015

Giyana, Frenti, 2012. Analisis Sistem Pengelolaan Rekam Medis Rawat Inap Rumah Sakit Umum Daerah Kota Semarang, Jurnal Kesehatan Masyarakat Volume 1, Nomor 2, Tahun 2012, Halaman 48-61.

Ghozali, Imam, 2005, Aplikasi Analisis Multivariat dengan Proses SPSS, BP Universitas Diponegoro, Semarang.

Hanafiah, Jusuf, \& Amir, Amri, 2008, Etika Kedokteran \& Hukum Kesehatan, edk 4, EGC, Jakarta.

Hatta, Gemala R., (ed.) 2012, Pedoman Manajemen Informasi Kesehatan di Sarana Pelayanan Kesehatan: Revisi Buku Petunjuk Teknis Penyelenggaraan Rekam Medis/Medical Record Rumah Sakit (1991) dan Pedoman Pengelolaan Rekam Medis Rumah Sakit di Indonesia (1994, 1997), edk 2, Penerbit Universitas Indonesia, UI - Press, Jakarta.

Huffman. EK, Health Information Management Tent Edition Illionis, Phycian Record Company, 1994. 
Indradi, Rano. Rekam Medis. Penerbit Universitas Terbuka, Edisi Dua, Tangerang Selatan, 2016.

Istirochah. 2016, Analisis Kepatuhan Dokter dalam Mengisi Berkas Rekam Medis di Rumah Sakit Umum Daerah Kabupaten Boyolali, Semarang, 2016. (Tesis)

Keputusan Menteri Kesehatan RI No: 034/Birhup/1972 yaitu di wajibkan semua rumah sakit untuk menyelenggarakan rekam medis (Depkes RI, 1997).

Lapau, Buchari. 2013. Metode Penelitian Kesehatan Metode Ilmiah Penulisan Skripsi Tesis dan Disertasi, Edisi Revisi, Jakarta 2013

Notoatmodjo, S. 2007. Pendidikan dan Perilaku kesehatan. Cetakan 2 Jakarta: PT.Rineka Cipta. 2007.

Peraturan Mentri Kesesehatan rupublik Indonesia Nomor 129/MENKES/SK/II/2008 tentang Rekam Medis

Peraturan Mentri Kesesehatan rupublik Indonesia Nomor 269/Menkes/Per/III/2008 tentang rekam medis

Puti Nazhifa Afdhal. 2014, Analisis Hubungan arakteristik Dokter Pengisi Rekam Medis Dengan Kelengkapan Rekam Medis Rawat Inap Bayi dan Anak di RSIA Budi Kemuliaan Tahun 2014. Jakarta. 2014

Rachma Y. Pengaruh Karakteristik Individu Dokter dan Masyarakat. 2010;4(1): 17-27. Petugas Pengembalian Berkas Rekam Medis (Pos Perawatan) terhadap Mutu Berkas Rekam Medis di Rumah Sakit Haji Jakarta tahun 2011. [Skripsi]. Universitas Indonesia, Jakarta. 2012

Ridho, Khasib Mabrur et al, 2012. Analisis Faktoor-faktor yang Mempengaruhi Kepatuhan Pengisian Rekam Medis di Rumah Sakit Gigi dan Mulut Pendidikan UMY, Yogyakarta, 2012.

Rina Yulida. 2016, Hubungan Karakteristik Dokter dengan Kelengkapan Catatan Laporan Operasi di RSU Queen Latifa Yogyakarta Tahun 2016, Yogyakarta. 2016. Jurnal Permata Indonesia Halaman 57-66 Volume 7, Nomor 2, November 2016

Sabarguna, Boy S. 2007, Sistem Informasi Manajemen Rumah Sakit: Edisi Revisi. Yogyakarta: Konsorsium Rumah Sakit Islam Jateng-DIY.

Singarimbun, M. dan Effendi, S. 1987, Metode Penelitian Survai, Penelitian, Pendidikan dan Penerangan Ekonomi Sosial, Jakarta.

Sugiyanto, Zaenal. 2006, Analisis Perilaku Dokter Dalam Mengisi Kelengkapan Data Rekam Medis Lembar Resume Rawat Inap Di Rumah Sakit Ungaran Tahun 2005. Megister Ilmu Kesehatan Masyarakat Konsentrasi Administrasi Rumah Sakit Universitas Diponegoro.

Sugiyono, Metode Penelitian Kuantitatif, Kualitatif, dan R\&D, Alfabeta Cetakan Keduapuluh tiga, Bandung, 2016

Sugiyono, Metode Penelitian Kombinasi (Mixed Methods), Alfabeta Cetakan Kesembilan, Bandung, 2017.

Sugiyono, Statistik untuk Penelitian, Alfabeta Cetakan Kelima, Bandung, 2003

Undang-Undang Republik Indonesia Nomor 44 tahun 2009 tentang Rumah Sakit (RS),

Wijaya. L., Health Record Management, Asembling Records, Quantitative and Qualitative Analisis, Jakarta, 1999.

http://www.revisealevel.co.uk/subjects/psychology-1/psychology/unit-5-socialpsychology/factors-affecting-obedience/ dibuka tanggal 16 Mei 2018. 